\title{
WYBÓR NAJLEPSZEGO PROJEKTU ZGŁOSZONEGO W RAMACH BO Z WYKORZYSTANIEM METODY WIELOKRYTERIALNEGO GRUPOWEGO PODEJMOWANIA DECYZJI AHP
}

\author{
MAREK KANNCHEN ${ }^{1}$ \\ AJP w Gorzowie Wielkopolskim \\ ${ }^{1}$ e-mail: mkannchen@ajp.edu.pl
}

\section{SŁOWA KLUCZOWE}

STRESZCZENIE
AHP, podejmowanie decyzji, decyzje grupowe, decyzje wielokryterialne

Artykuł prezentuje możliwość wykorzystania wielokryterialnego grupowego podejmowania decyzji metodą AHP w podejmowaniu takich decyzji, w których przy dokonaniu właściwego wyboru musimy rozpatrzyć różne warianty, oceniając je według różnych kryteriów. Musimy więc posiadać wiedzę na ich temat, nie zawsze podaną $\mathrm{w}$ sposób ilościowy, a ocena powinna być względnie obiektywna, czyli niezależna od preferencji i opinii pojedynczego decydenta.

W artykule przedstawiono metodę wykorzystania grupowego AHP w celu sklasyfikowania projektów zgłoszonych do realizacji w ramach budżetu obywatelskiego. Klasyfikacja ta pozwoli określić, które z projektów zdaniem ekspertów będą miały największy wpływ na zrównoważony rozwój miasta, a co za tym idzie - powinny być „wskazane” mieszkańcom jako te lepsze wśród projektów zgłoszonych.

\section{Wprowadzenie}

Budżet obywatelski pozwala na zaangażowanie w rozwój miasta jego mieszkańców. Zgłaszane w ramach tego budżetu projekty uwzględniają potrzeby lokalnej społeczności mieszkającej w obrębie danej ulicy, osiedla lub dzielnicy. Nie biorą jednak pod uwagę, że zarządzanie współczesnym miastem wymaga konieczności uwzględnienia licznych współzależności występujących między czynnikami warunkującymi efekty podejmowanych decyzji (Pełski, 1999). 
Zarządzający miastem muszą dbać o jego zrównoważony rozwój, uwzględniając jego otoczenie gospodarcze, społeczne i środowiskowe. Wymaga to wiedzy z licznych dziedzin, takich jak urbanistyka, gospodarka przestrzenna, ekonomika miasta, technika, ekologia, socjologia, psychologia społeczna, itp.

Aby zgłaszane w ramach budżetu obywatelskiego projekty uwzględniały również zrównoważony rozwój miasta, można wskazać mieszkańcom spośród zgłoszonych projektów te najlepsze dla miasta, dzielnicy, osiedla. Powstaje więc problem decyzyjny. Ponieważ w zrównoważonym rozwoju miastem należy uwzględnić wiedzę z wielu dziedzin, wskazane jest, by do oceny zgłoszonych projektów powołana została grupa ekspertów. Ponieważ projekty należy ocenić, uwzględniając różne kryteria, eksperci powinni dokonać wyboru najlepszego z nich za pomocą metodologii wielokryterialnego wspomagania decyzji grupowych.

Jedną z popularniejszych metod wspomagania decyzji wielokryterialnych jest metoda Analitycznego Procesu Hierarchicznego (AHP), mająca zastosowanie w podejmowaniu na szczeblu samorządowym podobnych decyzji, jak poruszone w niniejszym artykule. Przykładem jest tutaj wybór optymalnej funkcji dla fragmentu centrum Białegostoku (Kobryń, 2015), wybór tramwajów dla systemu miejskiego transportu zbiorowego (Kruszyński, 2012), wybór lokalizacji lotniska pasażerskiego w województwie podlaskim (Kobryń, 2015) czy wyznaczenie kierunku rozwoju gminy Rokietnica (Łuczak, 2010).

\section{Metodykka grupowege wspomaganania decyzi) wielolkryterialnych AHP}

Metoda AHP (ang. Analytic Hierarchy Process) została opracowana przez Saaty'ego na przełomie lat 70. i 80 . XX wieku. Jest wielokryterialną metodą rozwiązania problemu decyzyjnego opartą na teorii użyteczności (Saaty, 1980).

Metoda AHP polega na zdefiniowaniu problemu decyzyjnego, dla którego tworzy się następnie strukturę hierarchiczną. W strukturze tej problem decyzyjny dekomponowany jest na podcele (kryteria). W ten sposób tworzone są kolejne poziomy struktury hierarchicznej. Na końcu tej struktury znajdują się pełniące funkcję liści w powstałej strukturze warianty decyzyjne (Saaty, 1990).

Po utworzeniu struktury hierarchicznej, dokonując porównań parami, decydent określa swoje preferencje względem kryteriów, podkryteriów oraz wariantów tejże struktury. Opinię decydent przedstawia w postaci numerycznej za pomocą fundamentalnej skali porównań zaproponowanej przez Saaty'ego (tab. 1) w skali ocen od 1 do 9. Dokonując tzw. porównań parami, należy przestrzegać zasady, że wartość oceny dla elementu mniej ważnego (mniej preferowanego) jest odwrotnością wartości oceny elementu ważnego w opinii decydenta (respondenta, eksperta), czyli a $i j=1 /$ aji oraz a $i i=1$. W tej sytuacji ważniejsze elementy otrzymują oceny $3, \ldots 5, \ldots 9$ w zależności od nasilenia przewagi jednego nad drugim, elementy o mniejszej ważności (niżej preferowane) w ocenianych parach otrzymują wartości $1 / 3, \ldots 1 / 5, \ldots 1 / 9$. Elementy uznane przez decydenta za równoważne otrzymują ocenę 1 . 
Tabela 1. Fundamentalna skala porównań Saaty’ego

\begin{tabular}{|c|c|c|}
\hline Skala ważności & Definicja & Wyjaśnienie znaczenia \\
\hline 1 & równe znaczenie & $\begin{array}{l}\text { równoważność obu porównywanych elementów (oba elementy } \\
\text { w równym stopniu przyczyniają się do realizacji żądanego celu) }\end{array}$ \\
\hline 3 & $\begin{array}{l}\text { słaba lub umiarkowana } \\
\text { przewaga }\end{array}$ & $\begin{array}{l}\text { słabe (umiarkowane) znaczenie lub preferencja jednego ele- } \\
\text { mentu nad drugim (jeden element ma nieco większe znaczenie } \\
\text { niż drugi) }\end{array}$ \\
\hline 5 & mocna przewaga & mocna preferencja (znaczenie) jednego elementu nad innym \\
\hline 7 & bardzo mocna przewaga & $\begin{array}{l}\text { dominujące znaczenie lub bardzo mocna preferencja jednego } \\
\text { elementu nad drugim }\end{array}$ \\
\hline 9 & $\begin{array}{l}\text { ekstremalna lub absolutna } \\
\text { przewaga }\end{array}$ & $\begin{array}{l}\text { absolutne większe znaczenie (preferencja) jednego elementu } \\
\text { nad drugim (przewaga jednego elementu nad drugim jest na } \\
\text { najwyższym możliwym do określenia poziomie) }\end{array}$ \\
\hline $2,4,6,8$ & $\begin{array}{l}\text { dla ocen pośrednich pomiędzy } \\
\text { powyższymi wartościami }\end{array}$ & $\begin{array}{l}\text { czasami istnieje potrzeba interpolacji numerycznej kompromi- } \\
\text { sowych opinii, ponieważ nie ma dobrego słowa do ich opisania } \\
\text { (stosowane są wówczas wartości środkowe z powyższej skali) }\end{array}$ \\
\hline
\end{tabular}

Źródło: opracowanie własne na podstawie (Saaty, 1980).

Na podstawie procedury porównań parami przez decydenta konstruuje się kwadratowe macierze porównań parami $(n \times n) A=[a i j]$, w których wykonuje się $n(n-1) / 2$ porównań wariantów decyzyjnych względem kolejnych kryteriów oraz kryteriów względem siebie. Liczba porównań parami wynika z tego, iż na przekątnej macierzy „, elementów znajdują się jedynki (każde kryterium jest równoważne względem samego siebie), a połowa opinii to odwrotności. Jest to jeden ze sposobów porównań parami pozwalający na zmniejszenie ilości porównań stosowany w przypadku, gdy decydent ma do porównania dużą liczbę kryteriów na danym poziomie struktury lub dużą liczbę wariantów. Konstruowana jest konsekwentna (zgodna) macierz porównań parami. Dla macierzy tej spełniona jest zależność:

$$
\mathrm{a}_{i j}=\mathrm{a}_{i k} / \mathrm{a}_{j k} \text {, dla każdego } i, j, k=1, \ldots, n
$$

$$
\mathrm{A}=\left[\begin{array}{ccccc}
1 & a_{12} & a_{13} & \ldots & a_{1 \mathrm{n}} \\
1 / a_{12} & 1 & a_{23} & \ldots & a_{2 \mathrm{n}} \\
1 / a_{13} & 1 / a_{23} & 1 & \ldots & a_{3 \mathrm{n}} \\
\ldots & \ldots & \ldots & \ldots & \ldots \\
1 / a_{1 \mathrm{n}} & 1 / a_{2 \mathrm{n}} & 1 / a_{3 \mathrm{n}} & \ldots & 1
\end{array}\right]
$$

Każda taka macierz powinna być proporcjonalna, tzn. jeśli element aij zawiera wartość $a$, wtedy element aji powinien zawierać wartość $1 / a$. Ponadto elementy aii, jak wynika z tabeli porównań, powinny zawierać wartości jednostkowe (Saaty, 2005), a macierz powinna być dodatnia, czyli zawierać wartości z zakresu od 1 do 9 (Saaty, 2008).

Dla każdej macierzy porównań parami tworzony jest następnie iloczyn kwadratowej macierzy i wektora priorytetów porównań parami (3). Wektory priorytetów $w=(w 1, \ldots, w n)$ są obliczane z macierzy porównań parami za pomocą liczb ze wspomnianej wcześniej fundamentalnej 
skali porównań Saaty'ego (Saaty, 1980, 1995), a następnie przedstawia się je w formie macierzy znormalizowanych ocen $A=(w i / w j)$ i wprowadza do odpowiednich kolumn tzw. macierzy decyzyjnej. Równanie $A_{w}=c_{w}(3,4)$ ma rozwiązanie w, jeżeli c stanowi największą wartość własną macierzy $A\left(\lambda_{\max }\right) \cdot \lambda_{\max }$ jest miarą zgodności porównań, która odzwierciedla proporcjonalność preferencji:

$$
\begin{aligned}
A_{w} & =\left[\begin{array}{cccc}
1 & a_{12} & \ldots & a_{1 \mathrm{n}} \\
1 / a_{12} & 1 & \ldots & a_{2 \mathrm{n}} \\
\ldots & \ldots & \ldots & \ldots \\
1 / a_{1 \mathrm{n}} & 1 / a_{2 \mathrm{n}} & \ldots & 1
\end{array}\right]\left[\begin{array}{c}
w_{1} \\
w_{2} \\
\ldots \\
w_{n}
\end{array}\right]=c_{w} \\
A_{w} & =\left[\begin{array}{cccc}
w_{1} / w_{1} & w_{1} / w_{2} & \ldots & w_{1} / w_{n} \\
w_{2} / w_{1} & w_{2} / w_{2} & \ldots & w_{2} / w_{n} \\
\ldots & \ldots & \ldots & \ldots \\
w_{n} / w_{1} & w_{n} / w_{2} & \ldots & w_{n} / w_{n}
\end{array}\right]\left[\begin{array}{c}
w_{1} \\
w_{2} \\
\ldots \\
w_{n}
\end{array}\right]=c_{w}\left[\begin{array}{c}
w_{I} \\
w_{2} \\
\ldots \\
w_{n}
\end{array}\right]=c_{w}
\end{aligned}
$$

W kolejnym kroku obliczany jest wskaźnik spójności macierzy, tzn. badana jest globalna spójność macierzy na każdym poziomie hierarchii, czyli sprawdzenie, jak dalece spójna jest informacja przekazana przez decydenta przy konstruowaniu macierzy porównań. Dotyczy to zdefiniowanych preferencji na poziomie kryteriów, podkryteriów, jak i wariantów (alternatyw). Spójność preferencji jest związana z przechodniością ocen. Jeżeli dla danego decydenta wariant $a_{i}$ jest dwa razy lepszy od wariantu $a_{j}$ oraz cztery razy lepszy od wariantu $a_{k}$ względem kryterium $k$, wtedy według tego samego decydenta i względem tego samego kryterium wariant $a_{j}$ powinien być dwa razy lepszy od wariantu $a_{k}$. Podczas badania najpierw obliczany jest współczynnik spójności CI (ang. consistency index) według wzoru:

$$
C I=\frac{\lambda_{\max }-n}{n-1}
$$

gdzie:

$\lambda_{\max }$ - największa wielkość własna macierzy (Saaty, 1990).

Następnie posługując się wzorem:

$$
C R=\frac{C I}{R}
$$

obliczamy względny indeks spójności CR (ang. consistency ratio) (Pomerol, Barba-Romero, 2000). R jest tutaj stałą, której wartość jest zależna od wymiaru macierzy porównań. Przykładowe wartości losowego indeksu niezgodności obliczone na podstawie kilku tysięcy macierzy przedstawia tabela 2 (Saaty, 1980; Trzaskalik, 2006). 
Tahela 2. Wskaźniki zgodności

\begin{tabular}{cccccccccccc}
\hline Rząd macierzy & $n$ & 1 & 2 & 3 & 4 & 5 & 6 & 7 & 8 & 9 & 10 \\
\hline Losowy indeks niezgodności & $\mathrm{R}$ & 0 & 0 & 0,52 & 0,89 & 1,11 & 1,25 & 1,35 & 1,40 & 1,45 & 1,49 \\
\hline
\end{tabular}

Źródło: (Saaty, 1980; Trzaskalik, 2006).

Przyjmuje się, że wartość względnego indeksu spójności dla macierzy jest mniejsza lub równa $5 \%($ C.R. $\leq 0,05)$ dla macierzy kwadratowej $n=3$ elementy, a dla większych macierzy wynosi nie więcej niż 10\% (C.R. $\leq 0,10)($ Saaty, 2005). Dla takich wartości współczynnik niezgodności jest akceptowalny, a zastosowane porównania są zgodne. W przypadku wartości współczynnika C.R. większej niż 10\% zalecane jest powtórzenie niektórych lub wszystkich porównań w celu pozbycia się niezgodności porównań parami. Jeśli wartości C.I. i C.R. na poszczególnych poziomach hierarchii wynoszą 0 , przedstawione preferencje są idealnie spójne.

Niekorzystne jest przekroczenie wartości względnego indeksu spójności $10 \%$, jak również osiągnięcie wartości zerowych. W pierwszym przypadku mamy do czynienia z nadmierną rozbieżnością kryteriów, czyli względnej wagi kryteriów, podkryteriów i wariantów wyboru, i musimy dokonać ponownego porównania niektórych lub wszystkich elementów, natomiast w drugim ze zbyt sztywnym utrzymaniem własnych poglądów decydenta, co oznacza niewielką elastyczność (możliwość zmiany zdania) oraz niesie za sobą niebezpieczeństwo pominięcia niektórych aspektów procesu decyzyjnego mogących mieć wpływ na końcowy wynik.

Ostatnim etapem w metodzie AHP jest synteza otrzymanych wyników i wybór najlepszego wariantu, który w największym stopniu przyczyni się do realizacji przyjętego przez decydenta celu. W tej fazie znormalizowane bezwzględne oceny ważności agregowane są za pomocą addytywnej funkcji użyteczności $U i$. Użyteczność wariantu $i-U i$ opisuje udział tego wariantu w celu globalnym i jest syntetyczną, zagregowaną oceną określającą jego pozycję wśród pozostałych wariantów. Ostatecznym wynikiem procesu AHP jest uzyskanie rankingu, czyli zbioru uszeregowanych wariantów od najlepszego do najgorszego.

W przypadku grupowego podejmowania decyzji wielokryterialnych metodą AHP zależnie od sytuacji decyzyjnej wykorzystuje się jedno z trzech podejść. Pierwsze polega na uzyskaniu przez decydentów konsensusu przy każdym porównaniu. Drugie z nich na agregowaniu opinii ekspertów już na poziomie ocen cząstkowych względem poszczególnych kryteriów (Saaty, Shang, 2007). Trzecie natomiast polega na agregowaniu globalnych wektorów preferencji uzyskanych przez każdego z ekspertów oddzielnie (Saaty, 1999). Przy drugim i trzecim rozwiązaniu przy agregacji preferencji różnych ekspertów Saaty zaleca skorzystanie ze średniej geometrycznej (Saaty, 2004; Saaty, Vargas, 2011).

\section{Procedura badawcza}

Badanie rozwiązuje problem decyzyjny, jakim jest wskazanie najlepszego projektu z projektów zgłoszonych w ramach budżetu obywatelskiego. Ponieważ kryteria brane pod uwagę przy 
ocenie tych projektów nie są kryteriami ilościowymi, w badaniu posłużono się metodologią AHP jako najbardziej odpowiadającą grupowemu podejmowaniu decyzji wielokryterialnych w takim przypadku. Badaniu poddano następujące warianty decyzyjne: w1 - budowa nad Wartą Grodu Gorzów Wlkp. - Centrum Kultury Słowiańskiej, w2 - wyznaczenie siedmiu wzgórz na terenie Gorzowa z trwałym ich oznakowaniem, w3 - rewitalizacja parku Siemiradzkiego wraz z remontem „schodów donikąd”, w4 - zagospodarowanie terenu zielonego oraz schodów od ul. Orląt Lwowskich, w5 - remont ścieżki ze schodami od ul. Walczaka do Miejskiego Centrum Kultury wraz z odbudową toru saneczkowego przy ul. Zacisze. Warianty te zostały poddane ocenie z zastosowaniem kryteriów: ład przestrzenny i gospodarka nieruchomościami, modernizacja, rewitalizacja, ochrona środowiska i przyrody, sport, turystyka i rekreacja, kultura.

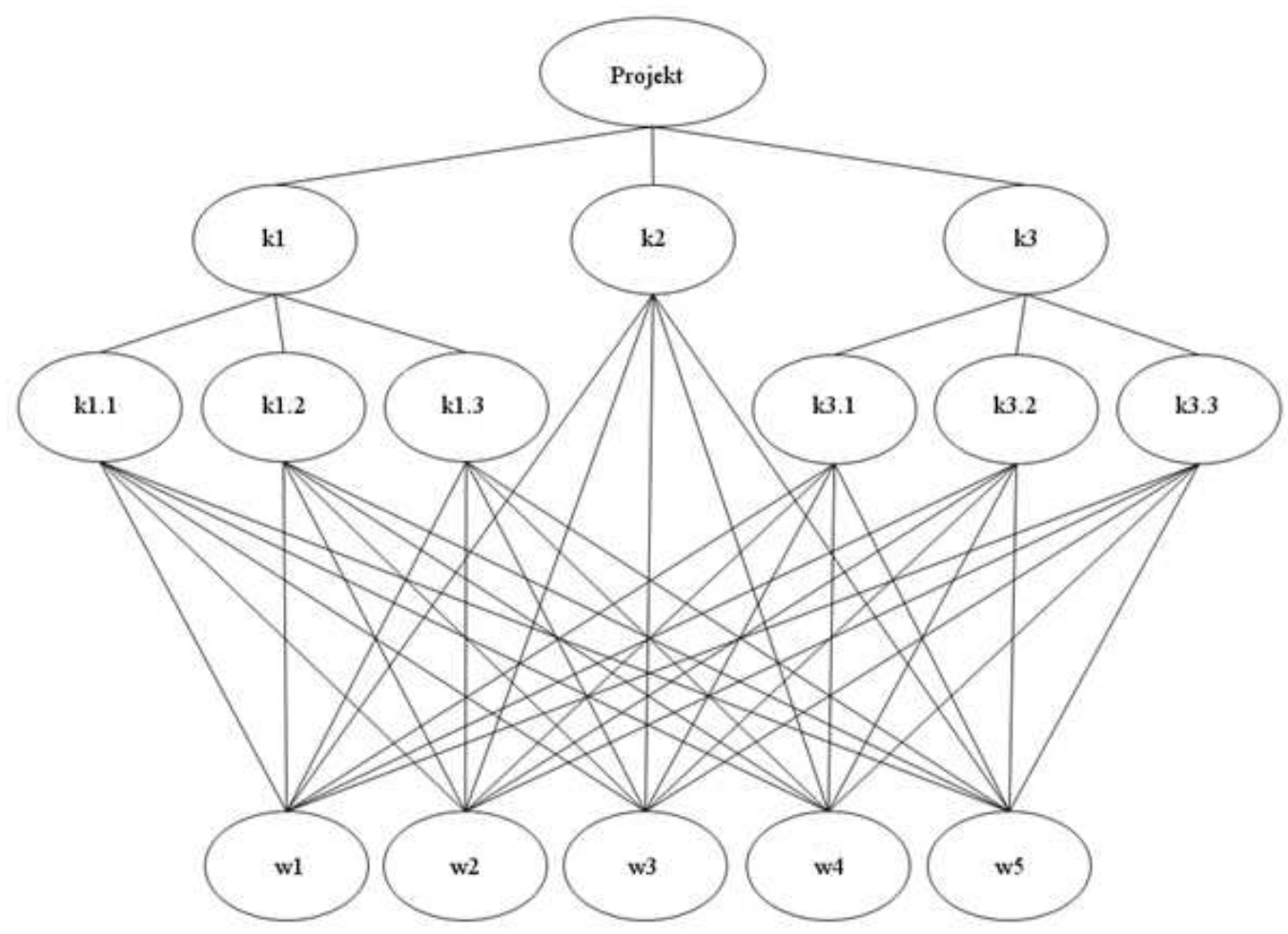

Rysunek 1. Struktura hierarchiczna rozpatrywanego problemu decyzyjnego

Źródło: opracowanie własne.

Ze względów na ilość porównań jakie musiałby wykonać każdy z decydentów przy zastosowaniu klasycznej metody AHP dla pięciu wariantów i siedmiu kryteriów, kryteria zostały przed badaniem poddane hierarchizacji. Wyznaczono trzy kryteria główne: k1 - prourbanistyczne, k2 - proekologiczne (ochrona środowiska i przyrody), k3 - prospołeczne oraz sześć kryteriów cząstkowych: k1.1 - ład przestrzenny i gospodarka nieruchomościami, k1.2 - modernizacja, k1.3 
- rewitalizacja, k3.1 - sport, k3.2 - turystyka i rekreacja, k3.3 - kultura. Struktura hierarchiczna rozpatrywanego problemu decyzyjnego przedstawiona jest na rysunku 1.

Na podstawie powyższej struktury hierarchicznej każdy z decydentów wykonał badanie składające się z czterech etapów. Etap I polegał na ocenie kryteriów względem siebie. Porównań dokonuje się parami z zastosowaniem skali ocen Saaty'ego, co zostało opisane powyżej. Osobnego porównania dokonano dla kryteriów cząstkowych wydzielonych z kryterium k1, z kryterium k3 oraz dla kryteriów głównych, w wyniku czego otrzymano trzy macierze porównań. Przykładową macierz porównań dla kryteriów przedstawia tabela 3.

Tabela 3. Macierz porównań dla kryteriów głównych

\begin{tabular}{lccc}
\hline \multicolumn{1}{c}{ Kryteria } & prourbanistyczne & proekologiczne & prospołeczne \\
\hline prourbanistyczne & 1 & 7 & 3 \\
proekologiczne & $1 / 7$ & 1 & $1 / 5$ \\
prospołeczne & $1 / 3$ & 5 & 1 \\
\hline
\end{tabular}

Źródło: opracowanie własne

Dla każdej macierzy porównań parami wyznaczono wektor preferencji, obliczono współczynnik spójności preferencji CI (ang. consistency index), a następnie współczynnik zgodności CR (consistency ratio) i dokonano sprawdzenia warunku CR $<0,1$. Jeżeli współczynnik CR nie spełnia wyżej wymienionego warunku, należy w takim przypadku dokonać ponownego porównania, zmieniając oceny w macierzy porównań.

W drugim etapie dokonano porównań parami wariantów względem siebie dla wszystkich kryteriów cząstkowych oraz dla kryterium głównego k2, w wyniku czego otrzymano siedem macierzy porównań. Przykładową macierz porównań dla wariantów przedstawia tabela 4 .

Tahela 4. Macierz porównań dla wariantów według kryterium K2

\begin{tabular}{cccccc}
\hline Warianty & W1 & W2 & W3 & W4 & W5 \\
\hline W1 & 1 & $1 / 3$ & $1 / 9$ & $1 / 7$ & $1 / 5$ \\
W2 & 3 & 1 & $1 / 7$ & $1 / 5$ & $1 / 3$ \\
W3 & 9 & 7 & 1 & 3 & 5 \\
W4 & 7 & 5 & $1 / 3$ & 1 & 3 \\
W5 & 5 & 3 & $1 / 5$ & $1 / 3$ & 1 \\
\hline
\end{tabular}

Źródło: opracowanie własne.

Tak jak w przypadku kryteriów, dla każdej z nich wyznaczono wektor preferencji, obliczono współczynnik spójności CI oraz współczynnik zgodności CR i dokonano sprawdzenia warunku zgodności. 
W trzecim etapie na podstawie wektora własnego macierzy dla wariantów i wag dla poszczególnych kryteriów cząstkowych dokonano agregacji ocen cząstkowych dla kryteriów k1 i k3, w wyniku czego otrzymano wektory skali.

W czwartym etapie na podstawie wektorów skali otrzymanych w trzecim etapie, wektora własnego macierzy dla kryterium k2 oraz wag kryteriów głównych obliczono wektor skali i na jego podstawie dokonano klasyfikacji poszczególnych projektów. Przykładowe wyniki oceny dla poszczególnych wariantów według kryteriów głównych przedstawia tabela 5.

Tabela 5. Wyniki oceny uzyskane przez decydenta 1 dla poszczególnych wariantów według kryteriów głównych

\begin{tabular}{ccccc}
\hline & $\mathrm{k} 1-$ prourbanistyczne & $\mathrm{k} 2$ - proekologiczne & $\mathrm{k} 3$ - prospołeczne & Wynik końcowy \\
\hline W1 & 0,05738938 & 0,03482081 & 0,41453735 & 0,15673984 \\
W2 & 0,05440698 & 0,06777767 & 0,23206535 & 0,10564209 \\
W3 & 0,4664698 & 0,5028195 & 0,14540894 & 0,37834285 \\
W4 & 0,26843524 & 0,26023159 & 0,06085569 & 0,20911844 \\
W5 & 0,1532986 & 0,13435044 & 0,14713267 & 0,15015679 \\
\hline
\end{tabular}

Źródło: opracowanie własne.

Kolejnym etapem badania była agregacja globalnych wektorów preferencji uzyskanych przez każdego z ekspertów oddzielnie (przedstawione w tab. 6) do wyznaczenia oceny grupowej. Do agregacji poszczególnych wektorów preferencji uzyskanych przez każdego z decydentów oddzielnie wykorzystano zalecaną przez Saaty’ego średnią geometryczną.

Tabela 6. Wektory preferencji uzyskane oddzielnie przez poszczególnych ekspertów

\begin{tabular}{cccc}
\hline & Decydent 1 & Decydent 2 & Decydent 3 \\
\hline W1 & 0,15673984 & 0,06040673 & 0,11445224 \\
W2 & 0,10564209 & 0,41761153 & 0,14984951 \\
W3 & 0,37834285 & 0,20396959 & 0,25974877 \\
W4 & 0,20911844 & 0,11613518 & 0,1808617 \\
W5 & 0,15015679 & 0,20187698 & 0,29508778 \\
\hline
\end{tabular}

Źródło: opracowanie własne.

\section{Wyniki badań}

W wyniku przeprowadzenia badań polegających na wyborze najlepszego projektu zgłoszonego w ramach budżetu obywatelskiego metodą wielokryterialnego grupowego wspomagania decyzji AHP obliczono, że biorąc pod uwagę preferencje poszczególnych decydentów, najlepszym projektem zgłoszonym w ramach BO będzie projekt w3 - rewitalizacja parku Siemiradzkiego wraz z remontem „schodów donikąd”, co przedstawia tabela 7. 
Tahela 7. Wyniki decyzji grupowej

\begin{tabular}{cccccc}
\hline Wariant & w1 & w2 & w3 & w4 & w5 \\
\hline Ocena końcowa & 0,102714 & 0,187682 & 0,271645 & 0,16377 & 0,207584 \\
\hline
\end{tabular}

Preferencje wariantu w3 względem pozostałych wariantów mają również odzwierciedlenie w głosowaniu przez poszczególnych decydentów, co pokazane jest na rysunku 2.

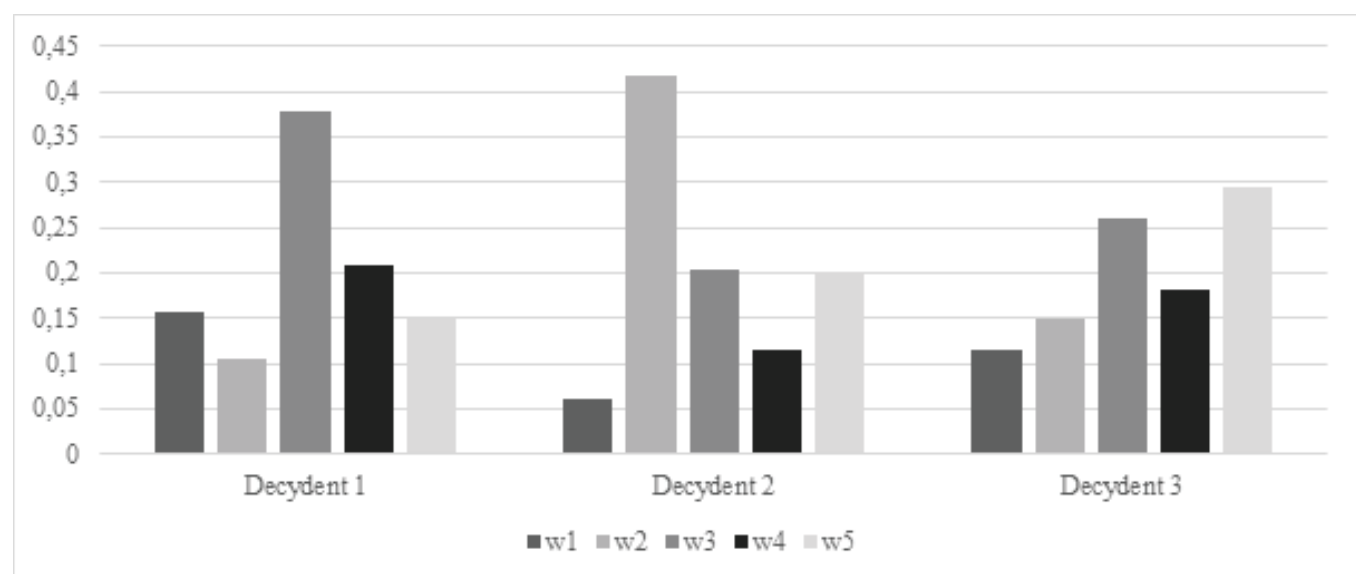

Rysunek 2. Klasyfikacja projektów według poszczególnych decydentów

Źródło: opracowanie własne.

Wynika z niego, że decydent 1 uznał w wyniku oceniania ten projekt za najlepszy, natomiast przez decydentów 2 i 3 projekt ten był wysoko oceniany i zajmował w ich rankingach drugie miejsce, co miało znaczący wpływ na ocenę końcową, ponieważ różnili się oni zasadniczo w ocenie pozostałych projektów.

Na drugim miejscu został sklasyfikowany projekt w5 - remont ścieżki ze schodami od ul. Walczaka do Miejskiego Centrum Kultury wraz z odbudową toru saneczkowego przy ul. Zacisze, na trzecim projekt w2 - wyznaczenie siedmiu wzgórz na terenie Gorzowa z trwałym ich oznakowaniem. Natomiast najsłabiej ocenione zostały projekty w4 - zagospodarowanie terenu zielonego oraz schodów od ul. Orląt Lwowskich oraz w1 - budowa nad Wartą Grodu Gorzów Wlkp. - Centrum Kultury Słowiańskiej.

\section{Podsumowanie}

W niniejszej pracy do oceny grupowej według wielu kryteriów wykorzystano metodę AHP. $\mathrm{W}$ artykule przedstawiono procedurę postępowania $\mathrm{w}$ grupowym podejmowaniu decyzji wie- 
lokryterialnych metodą AHP oraz zastosowano tę metodę w celu oceny projektów zgłoszonych w ramach budżetu obywatelskiego.

Jak wynika z powyższych badań, metoda AHP pozwala ocenić projekty, w których decydenci nie operują na jawnych danych ilościowych, a dokonywane przez nich oceny są ich indywidualnymi opiniami i preferencjami względem danego kryterium, co nie zawsze jest oceną obiektywną.

Dlatego też warto, jak wykazano w powyższym artykule, wykorzystać metodę grupowego wielokryterialnego podejmowania decyzji AHP. Metoda grupowa AHP pozwala w znacznym stopniu zobiektywizować taką ocenę poprzez skorzystanie z usług grupy ekspertów z wielu dziedzin zamiast pojedynczego eksperta. Grupa ekspertów posiada szerszą wiedzę, a niewielkie błędy popełnione przez jednego z ekspertów mogą zostać zneutralizowane poprzez oceny pozostałych decydentów. Należy jednak wziąć pod uwagę, że jeżeli jeden z ekspertów znacznie przeszacuje jakość jednego z wariantów, oceny pozostałych decydentów mogą okazać się niewystarczające do zneutralizowania popełnionej przez niego pomyłki.

Opinia ekspertów wskazuje, że najlepszym projektem w ramach projektów zgłoszonych do budżetu obywatelskiego jest projekt rewitalizacji parku Siemiradzkiego wraz z remontem „schodów donikąd”, a w następnej kolejności remont ścieżki ze schodami od ul. Walczaka do Miejskiego Centrum Kultury wraz z odbudową toru saneczkowego przy ul. Zacisze, wyznaczenie siedmiu wzgórz na terenie Gorzowa z trwałym ich oznakowaniem, zagospodarowanie terenu zielonego oraz schodów od ul. Orląt Lwowskich oraz budowa nad Wartą Grodu Gorzów Wlkp. - Centrum Kultury Słowiańskiej. Należałoby więc, mając na uwadze zrównoważony rozwój miasta, „wskazać” mieszkańcom powyższy ranking lub przyznać dodatkowe punkty najlepszemu projektowi/projektom, tak by to jednak mieszkańcy mogli zdecydować ostatecznie, które z projektów zostaną wybrane do realizacji w ramach $\mathrm{BO}$ w wyniku głosowania.

\section{Literatura}

Łuczak, A., Korsak, S. (2010). Programowanie rozwoju gminy z wykorzystaniem Analitycznego Procesu Hierarchicznego. Journal of Agribusiness and Rural Development, 3(17), 75-88

Kobryń, A., Tarnacka, K. (2015). Problem wyboru optymalnej funkcji fragmentu centrum Białegostoku. Problemy Rozwoju Miast - Kwartalnik Naukowy Instytutu Rozwoju Miast, I, 15-20.

Kobryń, A., Bakunowicz, K. (2015). Wielokryterialny model decyzyjny w wyborze lokalizacji lotniska pasażerskiego w województwie podlaskim. Ekonomia i Środowisko, 1 (52), 80-99

Kruszyński, M., Fierek, S., Żak, J. (2012). Zastosowanie koncepcji „dobrego zarządzania publicznego” do wyboru tramwajów dla systemu miejskiego transportu zbiorowego. Logistyka, 2, 807-819

Pełski, W. (1999). Zarządzanie zrównoważonym rozwojem miasta. Warszawa: Arkady.

Saaty, T.L. (1980). The analytic hierarchy process: Planning, priority setting, resource allocation. New York: McGrawHill International Book Co.

Saaty, T.L. (1990). How to make a decision: The Analytic Hierarchy Process. European Journal of Operational Research, 48, 9-26. 
Saaty, T.L. (1995). Transport Planning with Multiple Criteria. The Analytic Hierarchy Process Applications and Progress Review. Journal of Advanced Transportation, 29.

Saaty, T.L. (1999). The seven pillars of the analytic hierarchy process. ISAHP 1999-conference proceedings, 20-33.

Saaty, T.L. (2004). Decision making - the analytic hierarchy and network processes (AHP/ ANP). Journal of Systems Science and Systems Engineering, 13, 1, 1-35.

Saaty, T.L. (2005). The Analytic Hierarchy and Analytic Network Process for the measurement of intangible criteria and for decision-making. W: J. Figueira, S. Greco, M. Ehrgott (red.), Multiple Criteria Decision Analysis: State of the Art Surveys (s. 345-407). Boston: Springer Science.

Saaty, T.L., Shang, J.S. (2007). Group decision-making: Head-count versus intensity of preference. Socio-Economic Planning Sciences, 41, 22-37.

Saaty, T.L. (2008). Decision making with the analytic hierarchy process. International Journal of Services Sciences, $1,1,83-98$.

Saaty, T.L., Vargas, L.G. (2011). The possibility of group choice: pairwise comparisons and merging functions. Social Choice and Welfare. DOI: 10.1007/s00355-011-0541-6.

Trzaskalik, T. (2006). Metody wielokryterialne na polskim rynku finansowym. Warszawa: Polskie Wydawnictwo Ekonomiczne.

\section{CHOOSING THE BEST PROJECT SUBMITTED IN THE CONTEXT \\ OF BO USING THE METHOD OF MULTI-CRITERIA GROUP DECISION MAKING AHP}

\section{KEYWORDS | AHP, Analytic Hierarchy Process, group decision making, multi-criteria decision making}

ABSTRACT The article presents the possibility of using multi-criteria group decision making using AHP in making such decisions in which in order to make the right choice, we must consider different variants of assessing them according to various criteria. Therefore, we need to possess knowledge about them, which is not always given in a quantitative manner, and the evaluation should be relatively objective that is independent of the preferences and opinions of a single decision-maker. The article presents a method of using group AHP in order to classify the projects submitted for implementation under the civil budget. This classification will determine which of the projects, according to experts, will have the greatest impact on sustainable development of the city, and thus should be "pointed" to the inhabitants as the ones that are better among the projects submitted. 